\title{
CAFEICULTURA CIENTÍFICA GLOBALIZADA E AS MONTANHAS CAPIXABAS: A PRODU- ÇÃO DE CAFÉ ARÁBICA NAS REGIÕES DO CAPARAÓ E SERRANA DO ESPÍRITO SANTO
}

\section{Global Scientific coffee growing and the Montanhas Capixabas: the production of Arabic coffee gro- wing in Caparaó and Serrana regions of the Espírito Santo state (Brazil)}

Samuel Frederico

Prof. Dr., Departamento de Geografia, UNESP, Campus Rio Claro sfrederico@rc.unesp.br

Artigo recebido em 13/09/2012 e aceito para publicação em 10/10/2012

RESUMO: O propósito deste artigo é demonstrar a expansão e a consolidação da produção de café Arábica nas Montanhas Capixabas (ES), estabelecendo uma distinção entre as suas duas principais regiões produtoras: Serrana e Caparaó. Trata-se de uma cafeicultura secular produzida quase que exclusivamente por pequenos produtores, com o uso da mão de obra familiar e da parceria, conjugada com uma policultura de subsistência e voltada também para o abastecimento dos mercados locais. Apesar dessas características comuns e de sua proximidade geométrica, diferentes formas de uso e organização dos territórios das duas regiões legaram distintos recursos territoriais, que se expressam atualmente em diferentes formas de apropriação de valores materiais, simbólicos e de prestação de serviços personalizados para a produção cafeeira.

Palavras-chave:Cafeicultura; território usado; regiões produtivas; Montanhas Capixabas

ABSTRACT: The aim of this article is to demonstrate the expansion and consolidation of the Arábica coffee growing on the Montanhas Capixabas (ES), distinguishing its two producing regions: Serrana and Caparaó. These regions have many common features like a secular coffee production and smallholdings with a single family with a mixture of cash crops (principally coffee) and subsistence farming. However each region throughout its history had different ways of use and organization of their territories that enable distinct ways of appropriation of material, symbolic and in-person service attributes to coffee growing. Key-words:Coffee Growing; used territory; productive regions; Montanhas Capixabas 


\section{INTRODUÇÃO}

O objetivo deste texto é analisar a expansão e a consolidação da cafeicultura nas montanhas capixabas, estabelecendo uma distinção entre as suas duas principais regiões produtoras: Serrana e Caparaó. Trata-se de uma cafeicultura secular produzida quase que exclusivamente por pequenos produtores com o uso da mão de obra familiar e da parceria, conjugando a produção cafeeira com uma policultura de subsistência e voltada também para o abastecimento dos mercados locais. Apesar de ambas as regiões serem produtoras da espécie Arábica, diferentes formas de uso e organização de seus territórios desde a colonização, na segunda metade do século XIX, legaram distintas formações sócio-espaciais.

A noção de região é uma das mais antigas e polissêmicas na geografia (HAESBAERT, 2010). Na verdade, as diversas formas de se regionalizar são constantemente recriadas, coexistem, se sobrepõem e se articulam a cada momento da divisão territorial do trabalho, como aquelas de cunho natural, histórico-cultural, administrativo ou econômico (CORREIA, 1987; RIBEIRO, 2004). Nesta perspectiva, consideramos a região, como propõe Santos $(1985,2003)$, como um compartimento produtivo do espaço geográfico, fruto do embate cotidiano entre forças externas (verticalidades) e o conjunto pré-existente de relações solidárias estabelecidas numa área contígua (horizontalidades). Como assevera o autor (2003), a região perdeu o seu caráter autárquico, não que a concepção tradicional desconsiderasse totalmente os fatores exteriores na sua organização, mas no atual período da globalização, a força dos eventos externos é muito mais significativa na conformação do fato regional. Destarte, os compartimentos produtivos regionais tornam-se crescentemente submissos aos parâmetros internacionais de qualidade, organização, produtividade, logística e custos, que por sua vez promovem o aprofundamento da especialização produtiva, através da reunião de densidades técnicas (transporte, armazéns, máquinas, insumos químicos, tecnologias) e normativas (desonerações fiscais, leis ambientais e trabalhistas, certificações, selos de procedência).

Para alcançar seu objetivo, o artigo encontra-se dividido em três partes, além dessa introdução e das considerações finais. Na primeira parte, faz-se uma breve periodização da ocupação e consolidação da cafeicultura nas montanhas capixabas, diferenciando as colonizações pela imigração europeia, na Região Serrana, e pela itinerância dos cafeicultores mineiros e fluminenses, na Região do Caparaó. Ao caracterizar a produção cafeeira, destaca-se o período de crise e renovação da cafeicultura nas décadas de 1960 e 70, que transformou o estado do Espírito Santo no segundo maior produtor nacional do produto, e principalmente a emergência da cafeicultura cientifica globalizada a partir da década de 1990. Na segunda parte, analisa-se a especialização produtiva das montanhas capixabas com relação à cafeicultura e a dependência econômica de seus municípios, destacando os problemas relacionados à distribuição, produtividade, qualidade e organização dos produtores. Em seguida, na terceira parte, partindo-se da diferenciação entre recursos e ativos proposta por Benko e Pecqueur (2001), faz-se uma distinção entre as regiões produtivas do Caparaó e Serrana. Demonstra-se, como nesta última, a transformação de determinados recursos especificos em ativos tem agregado valor à produção cafeeira e criado novos canais de distribuição, através da valorização de seus atributos materiais (qualidades intrínsecas do produto), simbólicos (reputação) e de prestação de serviços personalizados (relação direta entre produtores e consumidores), como propõem Daviron e Ponte (2007).

\section{A SOBREPOSIÇÃO DE TEMPOS NAS REGI- ÕES CAFEEIRAS DO ESPÍRITO SANTO}

O espaço geográfico, sinônimo de território usado, pode ser entendido, segundo Santos (1996), como um "acúmulo desigual de tempos". Trata-se da coexistência, da sobreposição e da articulação em determinado lugar de sucessivas divisões sociais e territoriais do trabalho, isto é, de diferentes formas pelas quais o território foi usado em cada período. Para Isnard (1982, p.81), “(...) uma organização do espaço desaparece lentamente, resiste mesmo enquanto outra ocupa o seu lugar. É por isso, que num dado momento da evolução a sincronia dum espaço pode apresentar uma composição poligênica". No mesmo sentido, Silveira (1999) afirma que assim como um 
"palimpsesto", o espaço geográfico é a projeção de sucessivos usos do território que tiveram proeminência em cada período. Enquanto muitos desses usos desaparecem com o tempo, outros resistem como rugosidades (SANTOS, 1996), isto é, como heranças, contradizendo muitas vezes a lógica hegemônica atual.

O uso do território pela cafeicultura das montanhas capixabas é um exemplo de como heranças físico-territoriais e socioculturais pretéritas sobrevivem, se articulam e às vezes contradizem as formas dominantes do atual período. Mesmo com a difusão da cafeicultura moderna, em grandes propriedades, como aquela das áreas de cerrado do Triângulo Mineiro e do Oeste da Bahia, a produção cafeeira das montanhas capixabas continua a se reproduzir em grande parte de acordo com uma herança secular em que predomina a pequena propriedade agrícola, com o uso da mão de obra familiar, articulada com a prática de uma agricultura de subsistência.

Segundo Macedo e Magalhães (2011, p.64), apesar de ser uma área de ocupação antiga, os territórios que formariam o estado do Espírito Santo mantiveram-se praticamente isolados até a metade do século XIX, “(...) quando a cultura do café definiria sua dinâmica por 100 anos a partir da imigração estrangeira e pela estrutura de pequenas propriedades que se organizou a partir dela, interiorizando seu povoamento". Como analisado por Cano (2002), a introdução da cafeicultura no território capixaba ocorreu entre as décadas de 1840-60, em substituição à cana-de-açúcar. Todavia, o seu crescimento se deu de fato nas últimas décadas do século XIX, com o aumento do fluxo imigratório de produtores de Minas Gerais e do Rio de Janeiro, devido à itinerância da cafeicultura provocada pelo esgotamento das terras, e ao estímulo dado à imigração europeia, pelo governo provincial, através da formação de núcleos de colonização.

Neste último, a produção era camponesa, com o cultivo do café associado ao de subsistência. Nos latifúndios, ocupados pelos cafeicultores mineiros e fluminenses, apesar da sua grande dimensão, apenas uma pequena parcela das terras era ocupada pela cafeicultura, com o uso da mão de obra escrava. Segundo Cano (2002), com a abolição (1888), nada se alterou nas pequenas propriedades dos núcleos coloniais europeus, ao mesmo tempo em que parte das grandes fazendas se fragmentou em pequenas propriedades e adotou predominantemente o regime de parceria. A Figura 1 distingue as regiões Serrana e do Caparaó no estado do Espírito Santo.

Figura 1. Regiões cafeeiras do Caparaó e

Serrana, Espírito Santo

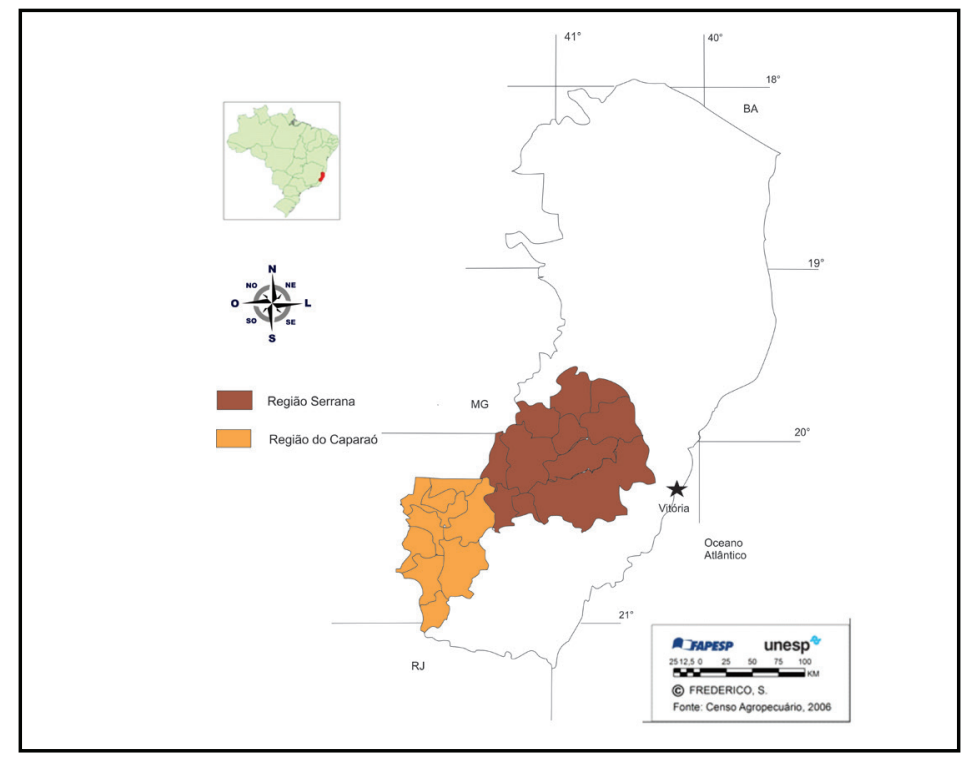


Sob o predomínio da pequena propriedade familiar e associado ao cultivo de subsistência, o café avançou para o norte do estado e para as terras de menores altitudes (com o cultivo da espécie Canephora), fazendo com que na década de $1950,75 \%$ dos estabelecimentos rurais capixabas tivessem na cafeicultura a sua principal atividade econômica (SEAG, 2008). Macedo e Magalhães (2011, p.82) ressaltam que apesar do seu baixo dinamismo econômico, a cafeicultura foi o "principal vetor de crescimento da economia do Espírito Santo e seu mais importante elemento de organização territorial até meados do século XX”. Segundo os autores, ela foi a responsável pela interiorização do povoamento, com o estabelecimento de uma rede urbana, ainda que incipiente; promoveu a expansão da fronteira agrícola interna, ocupando as terras ao norte do estado; e consolidou a cidade de Vitória como o principal lócus comercial e de serviços do estado.

\section{CRISE E RENOVAÇÃO DA CAFEICULTURA CAPIXABA (DÉCADAS DE 1960/70)}

$\mathrm{O}$ início da segunda metade do século XX ensejou profundas transformações na organização e uso do território brasileiro. A situação geográfica emergente se caracterizou pela difusão de uma psicoesfera, pautada na ideologia do consumo, do crescimento econômico e do desenvolvimentismo; e de uma tecnoesfera, por meio da construção de macrossistemas técnicos (rodovias, portos, sistemas de comunicação, usinas hidrelétricas, infraestruturas urbanas, indústrias, modernização agrícola), que possibilitou e exigiu uma maior fluidez e gradativa integração do território brasileiro (SANTOS, 1996). Na agricultura, vivenciou-se uma profunda transformação na sua base técnica, com a internalização do "paradigma da Revolução Verde" (PORTO-GONÇALVES, 2006), através do uso de cultivares altamente produtivos e resistentes à aplicação de insumos químicos; e a formação dos "complexos agroindustriais", com a integração da atividade agrícola com a indústria de bens de capital a montante e processadora a jusante (MULLER, 1989; MAZZALI, 2000).

Dentre as diversas culturas agrícolas objeto de modernização, o café possuía uma posição de destaque em meados do século XX, por se constituir como o principal produto brasileiro de exportação, responsável direto pela geração de divisas necessárias à industrialização (via substituição de importações), aos investimentos diretos do Estado para o desenvolvimento da indústria de base e à implantação dos sistemas de engenharia. A dependência com relação à economia cafeeira levou o Estado a patrocinar uma política de modernização e racionalização da cafeicultura, com o intuito de aumentar a produtividade, a despeito das sucessivas superproduções, recorrentes desde o início do século XX. Na década de 1960 foi criado o Grupo Executivo de Racionalização da Cafeicultura (GERCA), vinculado ao Instituto Brasileiro do Café (IBC), responsável pela criação e execução do Programa Nacional de Erradicação dos Cafezais e do Plano de Revigoramento e Renovação dos Cafezais (PRRC). Estas políticas promoveram a erradicação de quase metade da população cafeeira brasileira, sobretudo, das lavouras pouco produtivas ou localizadas em regiões consideradas inadequadas, e difundiram a produção de variedades mais produtivas e sensíveis ao uso dos insumos químicos e mecânicos (BACHA, 1988).

A cafeicultura capixaba encontrava-se depauperada na década de 1960. A baixa produtividade decorrente da presença de solos degradados, as tecnologias insuficientes ao controle de pragas e doenças (broca-do-café e ferrugem) e o esgotamento da fronteira agrícola interna ao norte do estado, somados aos baixos preços internacionais do café, evidenciavam a crise do modelo agrícola dominante desde o final do século XIX. Como decorrência, a adoção das políticas derivadas do Programa Nacional de Erradicação dos Cafezais reduziu em mais de $50 \%$ a quantidade produzida de café no estado durante aquela década. A dominância da pequena propriedade, o esgotamento dos solos e a dificuldade de promover uma diversificação produtiva no campo acentuou o êxodo rural e promoveu a crescente urbanização da capital e de seu entorno, que por sua vez, recebia grandes investimentos como a implantação do Porto de Tubarão e das usinas de pelotização de minério de ferro da Companhia Vale do Rio Doce.

Porém, a partir da década de 1970, a adoção de novos sistemas técnicos agrícolas, decorrente da 
reestruturação da pesquisa agropecuária no estado, e a expansão do cultivo da variedade Conilon (espécie Canephora) promoveram um aumento significativo da produção cafeeira. O Plano de Revigoramento e Renovação dos Cafezais (PRRC) foi o responsável pela introdução de novas técnicas de manejo, de cultivares mais produtivos e pela oferta de crédito rural nas áreas de Arábica, ao mesmo tempo em que a política estatal de estímulo ao aumento do consumo interno de café e a criação da indústria nacional de café solúvel criaram um grande mercado consumidor para a variedade Conilon.

Desde então, a produção de café no Espírito Santo teve um aumento contínuo e significativo tornando o estado o segundo maior produtor brasileiro. A figura 2 mostra a evolução da quantidade de café produzida no Espírito Santo entre 1900 e 2010, evidenciando os períodos de queda e elevação da produção.

Figura 2. Quantidade produzida de café (mil sacas/60kg), 1900 - 2010, Espírito Santo

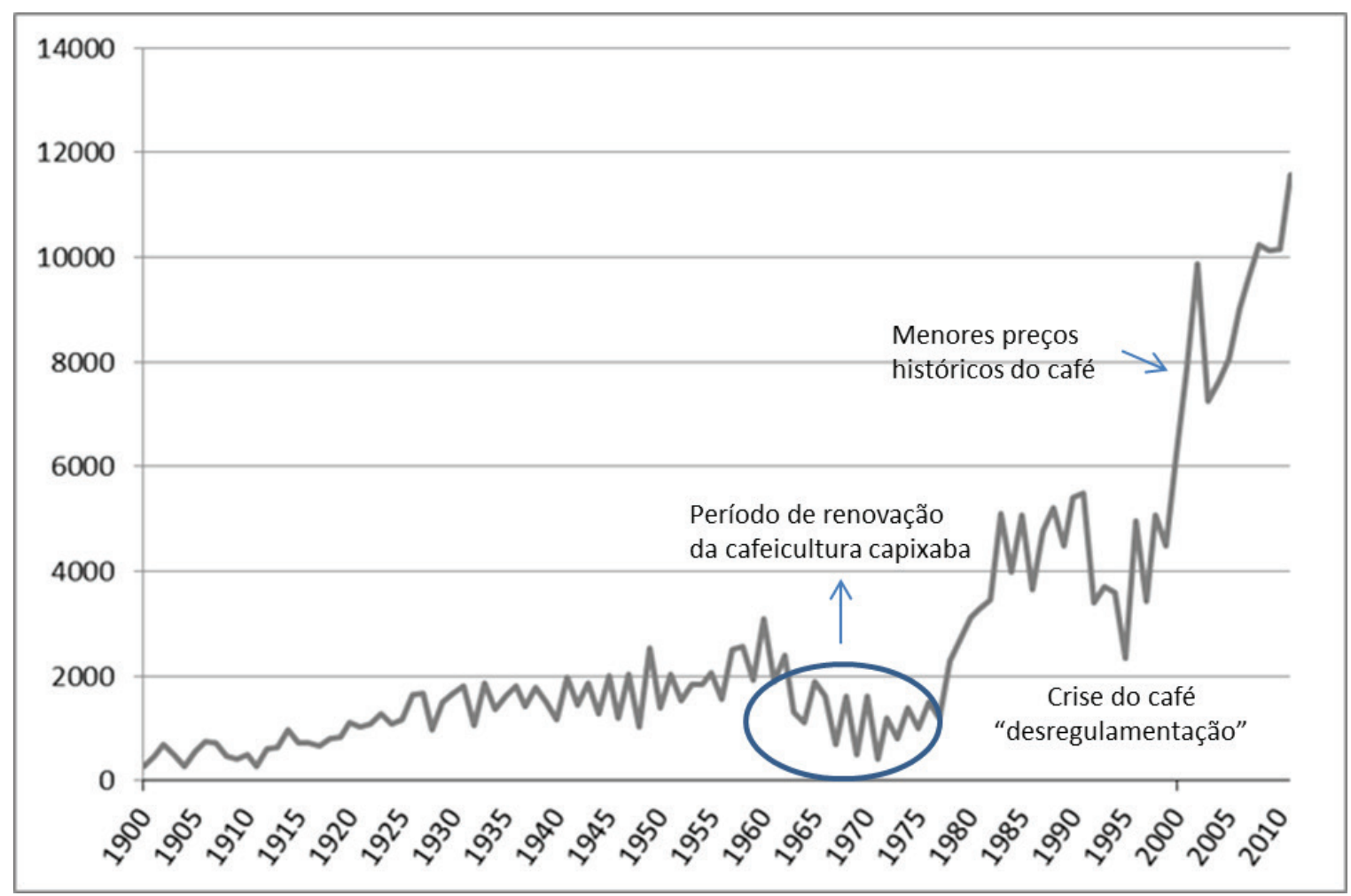

Fonte: Martins; Johnston (1992); IBGE/PAM (2010); INCAPER (2012).

A partir da segunda metade da década de 1970, as novas plantas oriundas do PRRC tornaram-se produtivas, promovendo um rápido aumento da quantidade produzida ao longo da década seguinte, alcançando 5,5 milhões de sacas na safra 1990/1991, numa área superior a 500 mil ha. Desde então, a quantidade produzida teve um aumento acentuado, interrompido por dois períodos de queda dos preços internacionais do café, sobretudo, no início das décadas de 1990 e 2000.

\section{CAFEICULTURA CIENTÍFICA GLOBALIZA- DA E A PRODUÇÃO CAPIXABA}

A década de 1990 marcou a substituição de uma cafeicultura herdeira do paradigma da Revolução Verde e fortemente regulada pelo Estado, dominante desde a década de 1960, por uma cafeicultura cientifica globalizada, caracterizada por grandes transformações de ordem política e técnica. Dentre as transformações de ordem política destacam-se a diminuição da intervenção estatal, com a extinção do Instituto Brasileiro do Café (1990) e dos Acordos Internacionais do Café 
(1989) - responsáveis pela definição de quotas de exportação para os países produtores, da montagem de estoques regulatórios e do controle dos preços nos mercados nacionais e internacionais -, e a estruturação de grandes corporações em verdadeiros oligopólios, na venda do café processado, e oligopsônios, na compra do grão verde, além da forte influência das especulações financeiras nas acentuadas oscilações dos preços internacionais do café cotados em bolsas de valores (TALBOT, 2004). Com relação às alterações de ordem técnica destacam-se a adoção das novas tecnologias da informação e da comunicação (NTIC) no campo, que além de permitirem o controle remoto da produção, redefinindo a autonomia e a hierarquia dos lugares, também viabilizaram o desenvolvimento de novos sistemas técnicos como a biotecnologia, a agricultura de precisão, o monitoramento de riscos climáticos e a criação de bancos de dados.

No caso específico da cafeicultura capixaba destaca-se o aumento expressivo da produtividade, com a adoção de novas técnicas de manejo e cultivares mais produtivos. A grande diferença entre o crescimento da produção verificado a partir de 1990, daquele existente em momentos anteriores, foi o aumento da quantidade produzida pelo incremento da produtividade, ao invés da incorporação de novas áreas. Entre 1970 e 1990, a produção aumentou de cerca de um milhão de sacas para mais de cinco milhões, com a expansão da área plantada de cerca de 200 mil ha para aproximadamente $500 \mathrm{mil}$ ha. No período de $1990 \mathrm{a}$ 2010, a quantidade produzida dobrou ao superar dez milhões de sacas na safra 2010/11, ao passo em que a área plantada teve uma pequena redução ficando em torno de 480 mil ha (MARTINS; JOHNSTON, 1992; IBGE, 2012). Observa-se, portanto, segundo Santos (1996), um aumento da "área" acompanhado de uma "redução da arena" de produção, isto é, a área abrangida pelas diferentes etapas do processo produtivo (produção, troca, distribuição e consumo) torna-se cada vez mais mundializada, ao passo em que a arena destinada ao processo produtivo propriamente dito diminui com o aumento da produtividade.

Apesar do grande crescimento da produtividade da cafeicultura capixaba - ao passar de 9,9 sacas/ha, na variedade Arábica, e 17,9 sacas/ha, na Conilon, em 2001, para 15,2 e 30,3 sacas/ha, respectivamente, em
2011 -, a produtividade do estado ainda é muito baixa quando comparada com a média nacional de 21 sacas/ ha, no caso do café Arábica. Os dados demonstram que as inovações tecnológicas e a assistência técnica aos produtores oferecida, sobretudo, pelo Instituto Capixaba de Pesquisa, Assistência Técnica e Extensão Rural (INCAPER) têm promovido o aumento do rendimento da cafeicultura, mas que ainda resta margem para um crescimento ainda maior.

As pesquisas desenvolvidas pelo INCAPER com a variedade Conilon começaram em 1985 e com os cafés arábicos, em 1998. No primeiro caso, destaca-se o desenvolvimento de variedades clonais e as novas técnicas de manejo como a redução do espaçamento, o plantio em linha, a introdução da irrigação, novas práticas de adubação e conservação dos solos. As unidades produtivas que utilizam os novos sistemas técnicos chegam a alcançar uma produtividade de até 100 sacas/ha.

Com relação à espécie Arábica, cultivada principalmente nas regiões montanhosas do Caparaó e Serrana, destacam-se os programas destinados ao aumento da produtividade e da qualidade do café, como: o Programa Renovar Arábica e o Programa de Melhoria da Qualidade do Café. O "Renovar Arábica" tem como objetivo renovar ou revigorar todas as lavouras do estado até 2025. A meta é duplicar a produtividade e a quantidade produzida, colhendo $30 \%$ de cafés de qualidade superior. Nos primeiros anos de implantação do Programa, entre 2007 e 2011, foi renovado mais de $10 \%$ do parque cafeeiro do estado, redundando num aumento superior a $50 \%$ tanto na quantidade produzida quanto na produtividade. Referente à qualidade do café destacam-se as parcerias entre produtores e o INCAPER para a melhoria das técnicas de colheita e pós-colheita, assim como a realização de concursos municipais e estaduais de qualidade.

\section{ESPECIALIZAÇÃO PRODUTIVA E O CAFÉ ARÁBICA DAS MONTANHAS CAPIXABAS}

Atualmente, o Espírito Santo é o segundo maior estado brasileiro produtor de café atrás somente de Minas Gerais. Como relatado anteriormente, apesar de sua origem centenária, a cafeicultura capixaba somente alcançou essa posição a partir da década de 
1970, com a renovação do café Arábica e a expansão das lavouras da variedade Conilon. Na safra 2010/11, o estado produziu pouco mais de 11,5 milhões de sacas, sendo 8,5 milhões de sacas de café Conilon, em cerca de 300 mil ha, e aproximadamente três milhões da espécie Arábica, em quase 200 mil ha. O estado é o principal produtor de café Conilon, com $76 \%$ do total da produção brasileira, e o terceiro maior produtor da espécie Arábica, com aproximadamente $10 \%$ do total (ABIC, 2011).

Praticamente todos os municípios do Espírito Santo produzem café. A cafeicultura é a principal atividade econômica em $80 \%$ dos 78 municípios capixabas, representando mais de $40 \%$ do Valor Bruto da Produção Agrícola do estado. A produção é predominantemente familiar, com tamanho médio das lavouras de 4,8 ha para o café Arábica e 9,4 ha para o
Conilon. No total, 131 mil famílias estão envolvidas somente na produção propriamente dita, em $60 \mathrm{mil}$ propriedades, com a geração anual de cerca de 400 mil empregos diretos (tratos culturais, colheita e pós-colheita) (INCAPER, 2012).

Enquanto o Conilon é cultivado em regiões de temperatura mais elevada, com média de $26^{\circ} \mathrm{C}$, e altitudes de até $500 \mathrm{~m}$, caraterísticas predominantes nas áreas litorâneas e ao norte do estado, o café Arábica é adaptado às regiões acima de $800 \mathrm{~m}$, com temperatura média de $20^{\circ} \mathrm{C}$. A última espécie é cultivada em 43 municípios, em cerca de 20 mil estabelecimentos agrícolas, localizados principalmente na região montanhosa do estado, próximo à divisa com Minas Gerais e Rio de Janeiro, como demonstra o mapa a seguir (Figura 3).

Figura 3. Municípios produtores de café Arábica e Conilon, Espírito Santo, 2006*

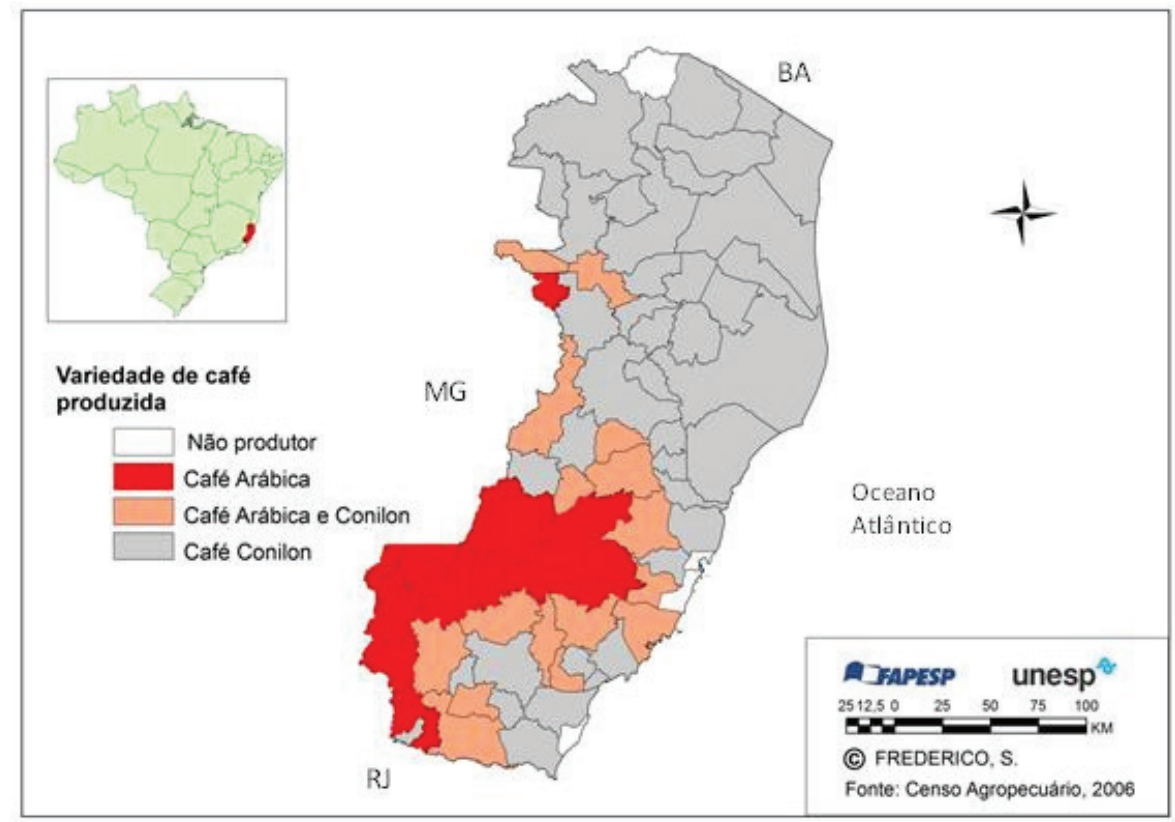

* Foram considerados municípios produtores de Arábica ou Conilon, aqueles em que $90 \%$ ou mais da área plantada correspondia a uma única espécie. Os municípios que apresentaram percentual de diferença inferior a $90 \%$ foram considerados produtores de ambos os tipos.

As plantações de café Arábica estão localizadas principalmente nas regiões montanhosas do Caparaó e Serrana, onde se encontra $75 \%$ da produção total. Os cinco principais municípios produtores da espécie (Iúna, Brejetuba, Vargem Alta, Irupi e Afonso Cláudio) foram responsáveis por cerca de $40 \%$ do total da espécie produzida no estado. Outra grande diferença entre as espécies Arábica e Conilon é o destino da produção. Enquanto, no primeiro caso, predominam as exportações, com $70 \%$ do total produzido, no segundo, apenas $30 \%$ é exportado, sendo os $70 \%$ restantes consumidos no mercado interno. 
Uma das principais características dos municípios produtores é a grande dependência econômica com relação à cafeicultura. No município de Iúna, maior produtor estadual da espécie Arábica, localizado na Região do Caparaó, quase $85 \%$ do valor do PIB agropecuário é proveniente somente da produção cafeeira. Dos 1.579 estabelecimentos agropecuários existentes no município, 1.363 unidades são produtores de café, cuja cultura ocupa cerca de $60 \%$ da área total dos estabelecimentos do município (em torno de 26 mil ha) (IBGE/Censo Agropecuário, 2006).
A significativa especialização produtiva também é recorrente em outros municípios produtores de café Arábica. O mapa a seguir (Figura 4) demonstra a relação entre a área plantada de café e a área total dos estabelecimentos agropecuários dos principais municípios produtores da espécie Arábica. Além de Iúna, descrito anteriormente, em outros quatro municípios (Ibatiba, Irupi, Brejetuba e Vargem Alta) a relação é superior a $50 \%$.

Figura 4. Relação entre a área plantada de café e a área total dos estabelecimentos agropecuários, 2006, Espírito Santo

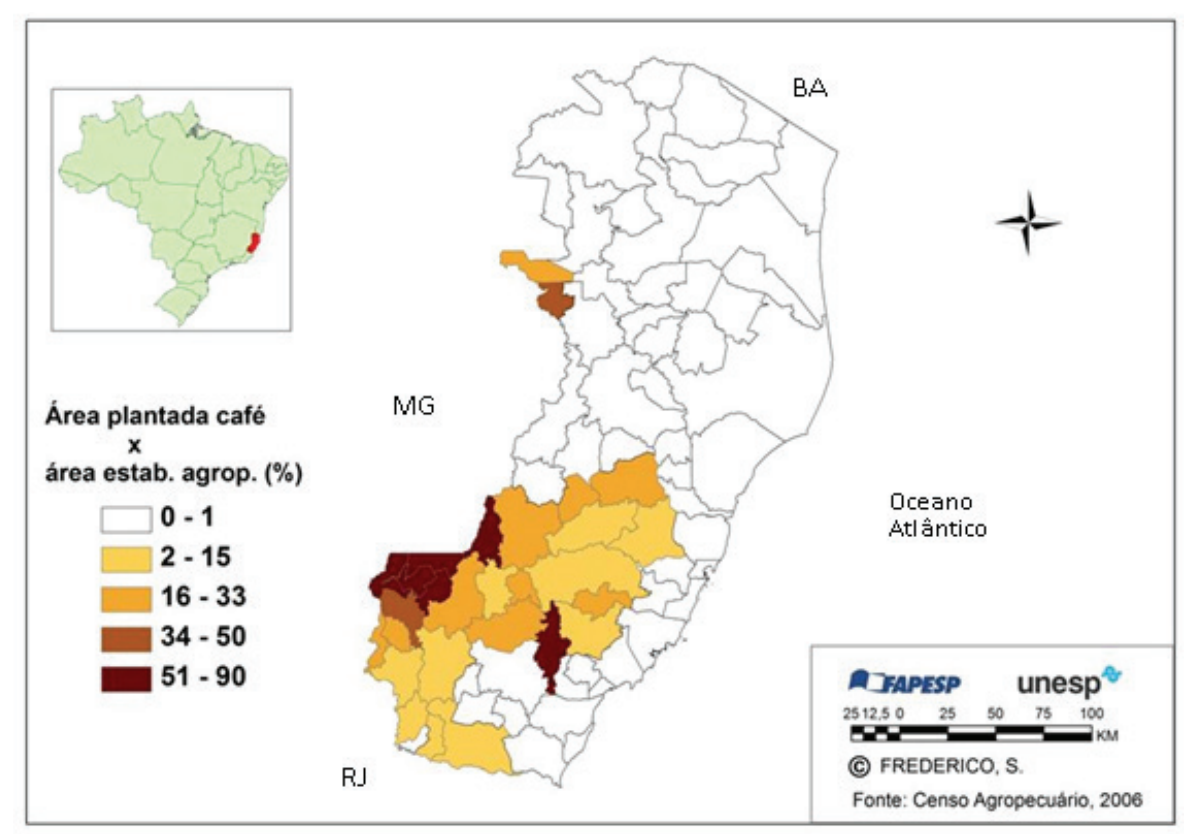

No ano de 2009, em todos os municípios supracitados, o valor da produção de café representou mais de $80 \%$ do valor total do PIB agropecuário (IBGE/Cidades, 2012). No caso de Brejetuba, município localizado na Região Serrana, o valor da produção cafeeira representa quase $100 \%$ do PIB agropecuário e mais de $50 \%$ do PIB total do município.

$\mathrm{Na}$ verdade, a produção cafeeira possui uma participação ainda mais significativa na dinâmica econômica desses municípios. Ao considerarmos o "valor da produção de café", estamos analisando apenas o valor gerado pela produção propriamente dita, não levamos em consideração a participação da produção cafeeira na indústria (agroindústrias de beneficiamento e torrefação), serviços (assessoria técnica, transporte, armazenagem, etc.) e comércio (revendas de insumos e máquinas agrícolas).

Apesar do sensível aumento da produtividade e da melhoria qualitativa do café Arábica capixaba na última década, estes indicadores ainda estão muito aquém daqueles alcançados por outras regiões brasileiras. Os esforços empreendidos pelo Estado, através das instituições públicas de pesquisa e extensão rural e governos municipais e estadual, têm resultado no crescimento significativo da produtividade - que passou de apenas cinco sacas/ha, em 1997, para uma média de 15 sacas/ha, em 2011 -, e também da qualidade através da produção de cafés especiais (gourmet, orgânico e 
Fair Trade). Todavia, a inércia produtiva faz com que as montanhas capixabas ainda obtenham os menores índices produtivos e qualitativos dentre as regiões produtoras de Arábica no território brasileiro, o que resulta em baixos preços recebidos pelos produtores (o menor entre as regiões produtoras de Arábica) e custos relativamente elevados por saca produzida.

A baixa qualidade do café fez com que no mês de agosto de 2011, quando o preço médio da saca negociada pelas demais regiões produtoras de Arábica foi superior a $\mathrm{R} \$ 400,00$, os produtores do município de Iúna recebessem um valor médio inferior a R\$ 250,00 . Os baixos preços recebidos por saca somados à pequena produtividade fez com que naquele mês o custo médio de produção no município fosse superior ao preço recebido por saca em $\mathrm{R} \$ 86,28$. Ou seja, mesmo num momento de alta dos preços do café, quando ele alcançou o maior valor médio dos últimos dez anos, a cafeicultura das montanhas capixaba, de uma forma geral, continuou deficitária (CNA, 2011).

Apesar dos custos de produção frequentemente serem superiores aos valores recebidos, diversos fatores contribuem para a manutenção da cafeicultura das montanhas capixaba: a falta de alternativa produtiva ao café, devido à forte declividade dos terrenos e ao tamanho reduzido dos estabelecimentos agropecuários; o enorme percentual de produtores proprietários que moram na propriedade e que utilizam sua própria força de trabalho nos tratos culturais do cafeeiro, intercalando a produção de café com culturas de subsistência e destinadas a abastecer o mercado local; a herança secular da produção cafeeira, que se por um lado gera resistência à adoção de novos sistemas técnicos pelos produtores, por outro, perpetua a prática da cafeicultura baseada num savoir-faire historicamente construído; e o regime de parceria, que elimina as despesas monetárias nos momentos mais intensivos em trabalho (colheita e pós-colheita).

No município de Iúna, por exemplo, os gastos com mão-de-obra (para a realização dos tratos culturais, colheita e pós-colheita), que em outras regiões montanhosas, como o Sul de Minas, representam mais de $50 \%$ do custo total, são praticamente inexistentes. Nesse município, o regime de parceria, adotado a mais de um século como solução para a falta de mão-de-obra com o fim do trabalho escravo, ainda é a solução para a manutenção da cafeicultura, ao reduzir significativamente o dispêndio monetário dos cafeicultores. O regime de parceria consiste basicamente num acordo firmado entre o proprietário e o parceiro, no qual o primeiro fica com $60 \%$ da produção e o segundo com os demais $40 \%$. O parceiro é responsável por todos os tratos culturais, colheita e pós-colheita, enquanto o proprietário arca com os gastos gerais e fornece os insumos.

Ao comparar os custos de produção de Iúna, com outros importantes municípios produtores de café, observa-se que o município capixaba possui o menor custo por hectare do país e que o custo por saca também é um dos menores, ficando atrás somente dos municípios de Altinópolis/SP, Luís Eduardo Magalhães/BA e Patrocínio/MG (CNA, 2011). Destarte, as principais questões a serem enfrentadas são o aumento da qualidade do café, para que se alcance melhores preços médios, e da produtividade, reduzindo os custos por saca. Não obstante, essas são as duas principais metas dos programas para a cafeicultura desenvolvidos atualmente pelo INCAPER.

A organização dos produtores em cooperativas e a busca pela produção de cafés especiais também são medidas essenciais para o aumento do preço médio recebido pela saca de café. Através das cooperativas, o café é separado em lotes de acordo com a qualidade e comercializado diretamente com as tradings ou torrefadores, eliminando os intermediários (comerciantes) locais e regionais, que compram o café dos produtores sem nenhuma diferenciação, pagando preços bem inferiores aos cotados pelo mercado. As cooperativas também possuem uma atuação importante no estímulo à melhoria da qualidade do café produzido através da assistência técnica e do fomento à produção de cafés especiais (Gourmet, orgânico e com certificação Fair Trade).

\section{TERRITÓRIO DE RECURSOS E O CAFÉ DAS MONTANHAS CAPIXABAS}

Apesar das características semelhantes presentes em todos os municípios produtores de café Arábica das montanhas capixabas, como a produção em pequenas propriedades, o uso da mão de obra familiar e da parceria e produtividades abaixo da média 
nacional, eles podem ser agrupados em duas regiões: Montanhas do Caparaó e Serrana. Trata-se de distintas regiões, com diferentes histórias de colonização, condições edafoclimáticas e organização dos produtores. As noções de ativos e recursos, propostas por Benko e Pecqueur (2001), podem nos auxiliar na diferenciação das duas regiões.

Para os autores, recursos são os fatores a "revelar", a "explorar", a "organizar", que possuem um "potencial latente", são atributos de reserva, ainda não ativados, não utilizados, como: reserva de matéria-prima, uma poupança potencial, um banco de dados, uma mão de obra não utilizada. A partir do momento em que os recursos são usados eles transformam-se em ativos, isto é, tornam-se existência. Para Silveira (2011), os ativos representariam o território sendo usado, enquanto os recursos seriam as "possibilidades históricas concretas" - heranças físico-territoriais ou sócio-culturais.

Os autores distinguem também os recursos e ativos em genéricos e especificos. Aqui, a principal distinção é que diferentemente dos recursos genéricos, facilmente transferíveis de um lugar a outro, os recursos específicos possuem uma forte "ancoragem" territorial, isto é, estão vinculados a um dado lugar, "resultam de uma história longa", de uma "acumulação de memória", sendo, portanto, "intransferíveis" e "incomensuráveis", cuja "emergência advém de regras e costumes, enfim, de uma cultura elaborada na contiguidade geográfica" (BENKO; PECQUEUR, 2001).

No caso da Região Serrana pode-se dizer que ela possui "recursos específicos" latentes, como: condições edafoclimáticas propícias para a produção de cafés de qualidade superior; uma identidade cultura singular e um savoir-faire vinculado às atividades agropecuárias decorrentes da colonização europeia; a presença de dezenas de pequenas "vilas rurais" $(65,6 \%$ da população é considerada rural pelo IBGE), o que estimula o associativismo; belezas paisagísticas e uma cultura própria que atrai e fortalece o agroturismo; a proximidade com a Região Metropolitana de Vitória, o que facilita o acesso aos serviços, à assistência técnica, ao mercado consumidor, aos eventos e exposições agropecuárias. Com o objetivo de agregar valor à produção cafeeira, alguns agentes locais vêm se esforçando para transformar esses "recursos espe- cíficos" em "ativos".

O objetivo principal das associações de produtores é agregar valor "material", "simbólico" e de "serviços personalizados" à produção cafeeira, de acordo com os termos utilizados por Daviron e Ponte (2007). Para os autores, os atributos "materiais" referem-se aos aspectos passíveis de serem medidos de maneira sensorial ou através de dispositivos tecnológicos, como: sabor, aroma, tamanho, cor, umidade, defeitos, impurezas. Os "serviços personalizados" referem-se às relações interpessoais entre os produtores e os consumidores, praticadas no agroturismo e nos bares-café. Já os atributos "simbólicos" derivam da reputação do produto, como a venda de uma mercadoria que valoriza a sua origem, o modo de vida, os saberes locais, uma forma de produção menos impactante aos recursos naturais e com melhor distribuição de renda. Geralmente, os atributos simbólicos são reconhecidos através de marcas comerciais, certificações (como do Comércio Justo ou ambiental) ou através de Indicações Geográficas.

Com relação à agregação de "valor material", somada às condições edafoclimáticas favoráveis da Região Serrana - como plantações em altitudes acima de $1.000 \mathrm{~m}$, temperaturas amenas e a presença de meses secos no período de colheita -, têm-se uma forte organização dos pequenos produtores familiares, o que facilita a difusão de boas práticas de manejo, como: uso de cultivares propícios, tratos culturais adequados, conservação do solo, destinação apropriada de resíduos, manejo correto de pragas e doenças e cuidados com o pós-colheita, como a produção de café cereja descascado. Como decorrência do manejo adequado, os cafés da Região têm se classificado entre os primeiros colocados nos concursos estaduais e nacionais de qualidade.

Entretanto, não basta somente produzir cafés de qualidade superior, é necessário que os compradores (corretores de café, tradings, cooperativas) reconheçam a qualidade do produto no momento da compra. Na maioria das vezes, os compradores limitam-se à reputação do produtor e da região e aos aspectos físicos facilmente mensuráveis (defeitos, impurezas, grãos ardidos, tamanho, cor). Daí a importância da constituição de associações formais de produtores, que além de classificar o café de acordo 
com seus aspectos degustativos e olfativos (sabor, doçura, corpo, acidez, aroma), também promovam a imagem do produto e possibilitem a comercialização do café em pequenos lotes de acordo com a qualidade do produto, agregando valor e diminuindo o poder de barganha dos atravessadores locais.

As associações e cooperativas de produtores também possuem um papel fundamental na valorização dos "atributos simbólicos" da produção cafeeira. Estes não são mensuráveis como os "aspectos materiais", eles dependem quase que exclusivamente da reputação dos produtores, do produto e da região. É mais um exemplo de "recurso específico", não "mensurável" e "intransferível", que resulta de uma construção histórica, um atributo do lugar. Com o objetivo de valorizar a reputação do café e da região, algumas associações e cooperativas têm desenvolvido diversas ações, como: a participação em concursos de qualidade e em feiras e exposições nacionais e internacionais, divulgando a qualidade e o nome da região; a busca pela certificação Fair Trade (Comércio Justo), que garante o pagamento de um preço mínimo para o café e assegura a qualidade e a origem do produto; a intenção de obter a Indicação de Procedência dos cafés das Montanhas Capixabas (a exemplo de outras regiões cafeeiras como o Cerrado Mineiro, a Alta Mogiana Paulista, o Norte Pioneiro Paranaense e a Região da Serra da Mantiqueira Mineira).

No caso da agregação de valor pelos "serviços personalizados", os produtores de café têm-se aproveitado do fato da Região Serrana ser a principal referência do agroturismo e do turismo de montanha do estado. Tradicionalmente, a Região sempre atraiu muitos turistas, principalmente da Grande Vitória, devido à proximidade, às suas belezas paisagísticas, ao clima de montanha e à identidade cultural singular dos descendentes dos colonos europeus, que se reflete entre outros na culinária, na arquitetura e nas festas típicas. Como decorrência, algumas iniciativas, como a criação de bares-café, na cidade de Venda Nova do Imigrante, têm sido tomadas com o objetivo de valorizar a qualidade e a diversidade dos cafés locais, oferecendo diferentes formas de consumir a bebida, além de outros produtos derivados do café, como sorvetes, bebidas frias, doces, etc. Outra forma de agregar valor pela prestação de serviços é o estímulo ao agroturismo nas tradicionais plantações de café, com a observação dos tratos culturais e a degustação da bebida.

Diferentemente da Região Serrana, os municípios do Caparaó localizam-se ao sul do estado, mais distantes da Capital Capixaba, cuja colonização se deu pela imigração de cafeicultores fluminenses e da Zona da Mata mineira, como ressaltado brevemente na primeira parte do texto. Os cafeicultores da Região enfrentam diversos problemas, desde climáticos como o excesso de umidade no período da colheita, o que dificulta a maturação homogênea dos grãos, comprometendo a qualidade final da bebida -, até organizacionais, devido à falta de tradição na formação de associações e cooperativas, o que os tornam, na maioria das vezes, reféns dos atravessadores locais.

Com relação aos aspectos materiais, os municípios do Caparaó são reconhecidos pela produção de cafés de qualidade inferior (Rio-Zona) - apenas 30\% da produção alcança bebida Dura, qualidade mínima exigida para exportação. Enquanto outras regiões brasileiras de cafés de montanha têm buscado a produção de cafés Gourmet (qualidade superior), os produtores das Montanhas do Caparaó encontram dificuldade para a produção de cafés com a qualidade mínima exigida pelos mercados internacionais. A má qualidade da bebida não é consequência apenas das dificuldades climáticas, mas principalmente da prática inadequada dos tratos culturais, colheita e pós-colheita, em que pese a pouca organização dos produtores e a falta de assistência técnica por parte dos institutos estaduais de pesquisa.

Sobre os atributos simbólicos, a Região é tradicionalmente reconhecida pela produção de cafés de qualidade inferior denominados pela Classificação Oficial Brasileira (COB) de bebida Riada, Zona ou Rio-Zona (antiga referência aos cafés produzidos nas regiões da Zona da Mata Mineira e do Rio de Janeiro). Os atravessadores locais se aproveitam da infâmia dos cafés regionais e da falta de organização dos produtores para rebaixar ainda mais os preços pagos, além de não realizarem nenhum tipo de classificação do produto no momento da compra. No que se refere aos "serviços personalizados", apesar do potencial da região, vinculado, sobretudo, à proximidade do Pico da Bandeira (terceiro mais alto do território brasileiro), existem poucas iniciativas locais ou por parte do 
Estado para a promoção do agroturismo ou mesmo do turismo de aventura.

\section{CONSIDERAÇÕES FINAIS}

O território, segundo Santos (1996), não é apenas normado pelas ações do presente, de caráter cada vez mais universal, ele é, em si mesmo, uma norma, função de sua estrutura e de seu funcionamento, de suas formas materiais e imateriais herdadas de momentos anteriores. A distribuição desigual das formas materiais (naturais e artificiais) somada às diferentes ações político-normativas permanecem no espaço como herança, como vestígios de projetos que se cristalizaram no território em períodos pretéritos. Trata-se, como sugere Silveira (2008, p.4), do território usado como norma, isto é, "um princípio ou um molde para a ação presente".

No caso das regiões capixabas do Caparaó e Serrana, apesar de sua proximidade geométrica e de serem produtoras de cafés arábicos, elas tiveram formações territoriais distintas, isto é, diferentes formas de uso e organização de seus territórios ao longo do tempo. Embora ambas tenham sido ocupadas pelo café na segunda metade do século XIX, na região Serrana a produção ocorreu pela implantação de núcleos de colonização europeia, enquanto no Caparaó, o café adentrou através da imigração dos produtores mineiros e fluminenses. Nesta última, a adjacência com o Rio de Janeiro e Minas Gerais fez com que os produtores sofressem uma forte influência dos estados vizinhos - ainda hoje, a cidade de Manhuaçu, na Zona da Mata Mineira, é a principal referência para o comércio de café dos municípios da Região -, ao passo em que os municípios da Região Serrana estabeleceram uma relação muito mais próxima com a capital Vitória. As diferentes formas com que os territórios foram sendo usados ao longo de mais de um século de colonização legaram diferentes formações territoriais, que redundaram em diferentes desafios e oportunidades para a efetivação dos projetos atuais.

Para os municípios do Caparaó as dificuldades edafoclimáticas, a assistência técnica incipiente e a prática de tratos culturais e pós-colheita inadequados têm resultado na produção de cafés de qualidade inferior, sendo necessário, portanto, a criação de políticas que visem à melhoria dos atributos materiais do café. Porém, não basta apenas melhorar a qualidade do café produzido, precisa-se também modificar as formas de distribuição e troca. Na situação atual, os pequenos cafeicultores não detém informação sobre a qualidade do café produzido, assim como estão presos a um sistema de comercialização através dos atravessadores (corretores) locais, que depreciam a qualidade e consequentemente os preços pagos aos produtores. Uma alternativa para essa situação seria o incentivo à criação de associações formais de produtores e cooperativas, que além de oferecerem assistência técnica, fizessem a comercialização e a classificação dos cafés antes da venda ("prova de xícara"), diminuindo a participação dos corretores locais.

Paralelamente à melhoria dos atributos materiais e das formas de comercialização do café, é preciso também criar políticas de valorização dos aspectos simbólicos e de prestação de serviços personalizados. No primeiro caso, é necessário reverter a imagem da Região de produtora de cafés de qualidade inferior, através da concepção e implantação de um modelo público de adequação e certificação das propriedades, a exemplo do programa Certifica Minas implementado pelo estado de Minas Gerais.

Com relação aos serviços personalizados, a situação ainda é muito incipiente. Existem algumas iniciativas na cidade de Iúna como a criação de bares-café, mas o mercado consumidor é muito reduzido, e apesar do potencial turístico da região, evidenciado pela proximidade com o Pico da Bandeira, os municípios da região não possuem uma boa infraestrutura turística, e mesmo se tivessem não é tão simples se apropriar do turismo como uma oportunidade para os pequenos cafeicultores.

No caso da Região Serrana, apesar de não ser uma referência nacional na produção de Arábica, ela se encontra em situação muito distinta da anterior. As condições edafoclimáticas propícias somadas à maior assistência técnica e à organização dos produtores têm resultado na produção de cafés de qualidade superior. No entanto, é necessário estimular ainda mais a filiação dos produtores às cooperativas e fortalecer as associações comunitárias de produtores familiares, com vistas à melhoria dos tratos culturais, colheita, pós-colheita e principalmente para a criação de novos 
canais de comercialização do café.

Com relação aos aspectos simbólicos, a Região é reconhecida pela cultura local singular, derivada da colonização europeia, e por um savoir-faire secularmente produzido atrelado à produção cafeeira, atributos que precisam ser valorizados e difundidos com o objetivo de agregar valor à produção. A criação de uma Indicação Geográfica poderia ser uma primeira alternativa para o reconhecimento das especificidades socioculturais e produtivas da Região. Por fim, a produção cafeeira também pode se transformar em mais um atrativo turístico, associado às belezas paisagísticas, à culinária e à cultura local. Através dos restaurantes, bares-café e do agroturismo é possível difundir o café produzido na região, agregando assim, mais um atributo de valorização à cafeicultura.

Contudo, o objetivo principal da proposição e execução de qualquer política pública deve ser assegurar a manutenção da estrutura de pequenas propriedades predominante nas duas regiões, que além do café produzem uma importante agricultura de subsistência e de venda do excedente para os mercados locais. Antes e para além do café, a questão central é o fortalecimento daqueles que vivem e se reproduzem nos lugares, isto é, dos pequenos produtores.

O café por representar a principal fonte de renda regional possui um papel de destaque, porém a crescente oscilação e depreciação dos seus preços nos mercados internacionais e a falta de uma política deliberada de regulação por parte do Estado tornam os produtores e os lugares extremamente vulneráveis. Não obstante, é crescente a importância do estímulo à diversificação produtiva pensada à luz do novo papel da circulação, ou seja, do acesso dos pequenos produtores aos meios de transporte, comunicação, informação e crédito e da criação de novas formas de comércio e distribuição. É necessário reconhecer, como propõe Milton Santos (1996), que o poder se concentra nas mãos daqueles que conseguem transformar a produção em fluxo, isto é, que controlam os meios de distribuição, a logística, o crédito e as informações estratégicas. Portanto, a pequena produção de base familiar precisa ser pensada diante da atual situação geográfica, ou seja, da sua fragilidade e vulnerabilidade com relação ao sistema econômico, bancário, de transportes, de distribuição, de preços e de fornecimento de assistência técnica, insumos e sementes. Daí a crescente importância do Estado como mediador desses fluxos produtivos, se almejamos a realização de uma política consequente de manutenção e reprodução dos pequenos produtores de base local.

\section{AGRADECIMENTOS}

$\mathrm{O}$ artigo resulta de pesquisa realizada com apoio da Fundação de Amparo à Pesquisa do Estado de São Paulo (FAPESP).

\section{REFERÊNCIAS}

ASSOCIAÇÃO BRASILEIRA DA INDÚSTRIA DE CAFÉ - ABIC. Estatísticas - Produção Agrícola. 2011. Disponível em: $<$ http://www.abic.com.br/publique/cgi/cgilua.exe/sys/start.htm?sid=48>. Consulta em: 11/09/2012.

BACHA, C.J.C. Evolução recente da cafeicultura mineira: determinantes e impactos. Tese (Doutorado em Economia). Faculdade de Economia e Administração da Universidade de São Paulo, São Paulo, 1988. 440 f.

BENKO, G.; PECQUEUR, B.. Os recursos de territórios e os territórios de recursos. Geosul, 16 (32), 2001. p. 31-50.

CANO, W. Padrões Diferenciados das Principais Regiões Cafeeiras (1850-1930). Ensaios sobre a Formação Econômica Regional do Brasil. Campinas: UNICAMP/IE, 2002.

CONFEDERAÇÃO DA AGRICULTURA E PECUÁRIA DO BRASIL - CNA. Relatório dos custos de produção das regiões cafeeiras. Brasília, DF, 2011.

CORREA, Roberto Lobato. Região e organização espacial. São Paulo: Ática, 1987.93 p.

DAVIRON, B.; PONTE, S. The coffee paradox: global markets, commodity trade and the elusive promise of development. Londres: Zed Books, 2007. 295 p. 
HAESBAERT, R. Regional-Global: Dilemas da Região e da Regionalização na Geografia Contemporânea. Rio de Janeiro: Bertrand Brasil, 2010. 208 p.

INSTITUTO BRASILEIRO DE GEOGRAFIA E ESTATÍSTICAS - IBGE. Cidades. 2012. Disponível em: <http://www.ibge.gov.br/cidadesat/topwindow. htm?1>. Consulta em: 11/09/2012.

INSTITUTO BRASILEIRO DE GEOGRAFIA E ESTATÍSTICAS - IBGE. Produção Agrícola Municipal. 2010. Disponível em: http://www.ibge.gov.br/home/ estatistica/economia/pam/2010/default.shtm. Consulta em: 11/09/2012.

INSTITUTO BRASILEIRO DE GEOGRAFIA E ESTATÍSTICAS - IBGE. Censo Agropecuário, 2006. Disponível em: http://www.ibge.gov.br/home/estatistica/economia/agropecuaria/censoagro/default.shtm. Consulta em: 11/09/2012.

INSTITUTO CAPIXABA DE PESQUISA, ASSISTÊNCIA TÉCNICA E EXTENSÃO RURAL - INCAPER. Setores do agronegócio - Café. 2012. Disponível em: http://www.incaper.es.gov.br/pedeag/setores03. htm. Consulta em: 11/09/2012.

ISNARD, H. O espaço geográfico. São Paulo: Almedina, $1982.258 \mathrm{p}$.

MACEDO, F. C.; MAGALHÃES, D. F. Formação econômica do Espírito Santo: do isolamento econômico à inserção aos mercados nacional e internacional. Revista de História Regional, 16(1), 2011. p.61-69.

MARTINS, M.; JOHNSTON, E.. 150 anos de café. São Paulo: Salamandra Consultoria Editorial, 1992. $391 \mathrm{p}$.

MAZZALI, L. O processo recente de reorganização agroindustrial: do complexo à organização "em rede”. São Paulo: Editora UNESP, 2000. 175 p.

MÜLLER, G. Complexo Agroindustrial e modernização agrária. São Paulo: HUCITEC, 1989. 149 p.
PORTO-GONÇALVES, C. W. A globalização da natureza e a natureza da globalização. São Paulo: Civilização Brasileira, 2006. 420p.

RIBEIRO, A. C. T. Regionalização: fato e ferramenta. In: LIMONAD, E.; HAESBAERT, R.; MOREIRA, R. (Org.). Brasil, século XXI - por uma nova regionalização?: Agentes, processos e escalas. São Paulo: Max Limonad, 2004b. p. 194-212.

SANTOS, M. A natureza do espaço: técnica e tempo, razão e emoção. São Paulo: Hucitec, 1996. 308 p.

SANTOS, M.. Região: Globalização e Identidade. LIMA, L.C. (Org.) Homenagem ao Geógrafo Cidadão do Mundo. Fortaleza: EDUECE, 2003. p. 53-64.

SECRETARIA DE ESTADO DA AGRICULTURA, ABASTECIMENTO, AQUICULTURA E PESCA - SEAG. Plano Estratégico de Desenvolvimento da Agricultura: novo PEDEAG 2007-2025. Vitória: SEAG, 2008. 284p.

SILVEIRA, M. L. Um país, uma região: fim de século e modernidades na Argentina. São Paulo: FAPESP/ LABOPLAN-USP, 1999.

SILVEIRA, M. L. Globalización y território usado: imperativos y solidariedades. Cuadernos Del Cendes, ano $25, n^{\circ} 69$, Set/Dec. 2008. p. 1-19.

SILVEIRA, M. L. Território usado: dinâmicas de especialização, dinâmicas de diversidade. Ciência Geográfica, Bauru, XV, Vol. XV (1), Jan./Dez., 2011. p. 04-12.

TALBOT, J. M. Grounds for agreement. The political economy of the coffee commodity chain. Lanham, MD: Rowman and Littlefield Publishers, INC. 2004. $237 \mathrm{p}$.

Soc. \& Nat., Uberlândia, 25 (1): 7-20, jan/abr/2013 